University of Nebraska - Lincoln

DigitalCommons@University of Nebraska - Lincoln

Faculty Publications, Department of Child, Youth, and Family Studies

Child, Youth, and Family Studies, Department of

8-2021

Examining correlates of feeding practices among parents of preschoolers

Deepa Srivastava

Lucy R. Zheng

Dipti Dev

Follow this and additional works at: https://digitalcommons.unl.edu/famconfacpub

Part of the Community Health and Preventive Medicine Commons, Developmental Psychology

Commons, Family, Life Course, and Society Commons, Nutrition Commons, Other Psychology Commons, and the Other Sociology Commons

This Article is brought to you for free and open access by the Child, Youth, and Family Studies, Department of at DigitalCommons@University of Nebraska - Lincoln. It has been accepted for inclusion in Faculty Publications, Department of Child, Youth, and Family Studies by an authorized administrator of DigitalCommons@University of Nebraska - Lincoln. 


\title{
Examining correlates of feeding practices among parents of preschoolers
}

\author{
Deepa Srivastava, ${ }^{1}$ Lucy R. Zheng, ${ }^{2}$ and Dipti A. Dev ${ }^{3}$ \\ 1 Nutrition, Family \& Consumer Sciences Advisor, Cooperative Extension, \\ University of California Agriculture \& Natural Resources, Davis, CA, USA \\ 2 Department of Psychology, University of California, Davis, CA, USA \\ 3 Department of Child, Youth and Family Studies, University of Nebraska-Lincoln, \\ Lincoln, NE, USA \\ Corresponding author - Deepa Srivastava, Ph.D., Nutrition, Family \& Consumer Sciences \\ Advisor, Cooperative Extension, University of California Agriculture \& Natural \\ Resources, 4435-B South Laspina Street, Tulare, CA 93274, USA. email dsr@ucanr.edu \\ ORCID \\ Deepa Srivastava https://orcid.org/0000-0002-7447-2540
}

\begin{abstract}
Background: Parent feeding practices play a critical role in children's eating behaviors. Limited research has explored child-level correlates of parent feeding practices.

Aim: To identify correlates of feeding practices (responsive and controlling) among parents of preschoolers US.

Methods: Participants included parents ( $\mathrm{n}=273$ ) of preschoolers (3-5 years), recruited from Early Care and Education settings $(n=24)$ located in a metropolitan city in the US. Analysis included descriptives, correlations, and multiple regression.

Results: For responsive feeding practices, positive associations included child's weight with unintentional modeling ( $\beta=.17,95 \% \mathrm{CI}[0.12,0.53])$, child vegetable consumption with behavioral role modeling ( $\beta=0.22,95 \% \mathrm{CI}[0.17,0.44])$, and parent monitoring with verbal modeling $(\beta=0.21,95 \% \mathrm{CI}[0.12,0.34])$. For controlling
\end{abstract}

Published in Nutrition and Health, 2021

DOI: $10.1177 / 02601060211032886$

PMID: 34424083

Copyright (C2021 Deepa Srivastava, Lucy R. Zheng and Dipti A. Dev. Published by SAGE Publications. Used by permission.

Published August 23, 2021. 
feeding practices, parent restriction was positively associated with child weight concern $(\beta=0.22,95 \% \mathrm{CI}[0.13,0.39])$ and parent monitoring $(\beta=0.13,95 \% \mathrm{CI}[0.01$, $0.19])$, whereas child vegetable consumption was negatively associated $(\beta=-0.16$, $95 \% \mathrm{CI}[-0.27,-0.05])$. Pressure to eat was negatively associated with child weight concern $(\beta=-0.18,95 \% \mathrm{CI}[-0.45,-0.09])$, child fruit consumption $(\beta=-0.12,95 \%$ CI $[-0.37,-0.01])$, household income $(\beta=-0.13,95 \%$ CI $[-0.30,-0.02])$, and parent weight $(\beta=-0.14,95 \% \mathrm{CI}[-0.60,-0.05])$,

Conclusions: Findings highlight the importance of child characteristics when examining correlates of parent feeding practices, demonstrating bidirectional interactions between parent feeding practices and children's eating behaviors. Considering childlevel correlates may improve the implementation of responsive feeding practices and reduce controlling feeding practices.

Keywords: Parents, preschoolers, correlates of feeding practices, childhood obesity prevention, responsive feeding practices

\section{Introduction}

Childhood obesity remains a serious public health issue in the United States. Nationally, the childhood obesity rate is $13.9 \%$ among 2 - to 5 -year-olds, putting millions of young children at greater risk for serious physical and mental health problems that can last a lifetime (Fryar et al., 2018). Children's poor eating habits are a risk factor for excessive weight gain and most children in the United States have suboptimal dietary adequacy and are not meeting nutritional recommendations (Centers for Disease Control and Prevention, 2014). Parents play an important role in shaping children's eating behaviors and prevent childhood obesity through their feeding practices in several ways including controlling availability and accessibility of foods in the home and by being their role models, agents of change, and educators (Birch and Davison, 2001; Golan, 2006; Hughes et al., 2005; Larson and Story, 2009; Vaughn et al., 2016).

Feeding practices refer to specific behaviors or strategies that parents use to influence children's food choices and acceptance patterns, eating behaviors, and weight status and can be broadly categorized into responsive and controlling feeding practices (Birch et al., 2001; Vaughn et al., 2016). Parents' responsive feeding practices is characterized by caregiver guidance and recognition of children's hunger cues and satiety, and parents' involvement that promotes children's healthy eating behaviors (Hughes et al., 2005). Examples of responsive feeding 
practices includes household availability and accessibility of fruits and vegetables (Wyse et al., 2011), allowing children to control the amount of food they eat (Hughes et al., 2005), and modeling healthy eating (Goldman et al., 2012; Palfreyman et al., 2014). On the other hand, parents' controlling feeding practices refers to the extent to which parents show control and supervision in their feeding practices (Hughes et al., 2005), with little regard for the child's choices and preferences (Patrick et al., 2005). Controlling feeding practices may include pressure to eat and food restriction that are linked to negative outcomes in terms of eating behavior and weight status (Birch et al., 2001; Faith et al., 2004). Pressure to eat refers to pressuring children to eat more food and restriction refers to limiting access and intake of high sugar, high fat foods and the child's favorite foods and restricting the total amount of food intake (Birch et al., 2001).

Research has shown that many parental factors are associated with feeding practices such as parent age (Bante et al., 2008), parent education, (Brown et al., 2008), family income and child gender (Francis et al., 2001), feeding attitude and controlling practices (Birch et al., 2001; May et al., 2007), perceived child weight status (Birch and Fisher, 2000), and feeding styles (Hughes et al., 2005). While studies have examined the association between parental feeding practices and children's dietary outcomes and childhood obesity (Birch et al., 2001, Birch and Davison, 2001; Golan, 2006; Haines et al., 2018), the focus of these studies is more on controlling than responsive feeding practices (Birch et al., 2001; Birch and Davison, 2001; Birch and Fisher, 2000). Addressing correlates of feeding practices can be a target for childhood obesity prevention interventions and may help improve parents' use of responsive feeding practices and reduce controlling feeding practices.

Taken together, although feeding practices in the home environment offer opportunities to shape children's eating behaviors (Vaughn et al., 2016), research in this field has predominantly focused on controlling feeding practices than responsive feeding practices and limited research has explored child-level correlates of parental feeding practices. The present study examined the association of responsive and controlling feeding practices with child and parent level characteristics such as child gender, child fruit and vegetable consumption, household income, parent feeding attitudes and monitoring, home meal preparation. The overall purpose of this study was to identify the correlates of responsive and 
controlling feeding practices among parents of preschoolers recruited from ECE centers located in a metropolitan city in the US. In this crosssectional study, correlations do not imply causal relationships.

\section{Methods}

\section{Participants and settings}

Using a correlational research design (Plano Clark and Creswell, 2010), cross sectional survey data was obtained from parents $(\mathrm{n}=273)$ of children ages 3-5 years, recruited from twenty-four Early Care and Education (ECE) centers located in a metropolitan city in the US. The University Institutional Review Board (IRB) approved all protocol and procedures prior to the initiation of this study.

\section{Data collection procedure}

The first author obtained the list of ECE centers from the program coordinator of Nutrition and Physical Activity Self-Assessment for Child Care (Go NAPSACC) which included the zip codes of the ECE centers from different parts of the city who had participated in Go NAP SACC. The Go NAPSACC program is an evidence-based intervention which provides ongoing guidance to promote healthy eating and physical activity behaviors across ECE settings. The Go NAPSACC coordinator introduced the first author and the study to the ECE center directors. Finally, the first author contacted the ECE center directors via telephone to confirm their participation and to get the total count of parent packets needed to distribute to parents who had at least one child in the age group 3 to 5 years old enrolled in their center.

Data were collected between June 2015 and November 2016. The first author provided director and parent packets to ECE center directors. Director packets included a letter explaining the study, two flyers advertising the study, a $\$ 50$ cash incentive for the center, and a receipt. Program directors were asked to post flyers advertising the study in the program and to distribute the surveys to parents. Parent survey packets $(n=862)$ were given to the ECE center directors $(n=24)$ to distribute to parents. Inclusion criteria for parents to participate in this survey 
was having at least one child 3-5 years of age. Parent survey packets included the letter explaining study purpose and procedure, a survey, a copy of the consent form, a $\$ 1$ bill, and fruit and vegetable stickers for preschool-age children. Parents were asked to read and keep the consent form. A waiver of signed informed consent was obtained from the IRB. Parents could opt out of the study by not returning the survey. Of the 862 parent surveys distributed, 273 were completed and returned via postage paid envelope. To ensure confidentiality, each survey was identified with an ID number, and no names appeared on the survey. The researcher asked the ECE center directors to send three email reminders to parents, one every 15 days.

\section{Measures}

Demographics. Demographic information of parents and their preschoolage child were collected. These demographic questions included parents' age (in years), gender, birthplace, race/ethnicity, marital status, education of parent and spouse, household income, parents' employment status, child age (in years), and child gender.

Child Feeding Questionnaire (CFQ; Birch, et al., 2001). The CFQ was used to measure parent attitudes, concerns, and practices regarding child feeding. The CFQ is a 28-item self-report parent questionnaire including seven subscales: perceived responsibility ( 3 items; $\alpha=0.89$ ); parent perceived weight ( 4 items; $\alpha=0.71$ ); perceived child weight ( 3 items; $\alpha=0.71$ ); parents' concerns about child's weight ( 3 items; $\alpha=0.77$ ); parent monitoring ( 3 items; $\alpha=0.91$ ), parent pressure to eat ( 4 items; $\alpha=0.77$ ), and parent restriction ( 8 items; $\alpha=0.73$ ). Parent controlling feeding practices were measured by pressure to eat ( 4 items), and restriction (8 items). All items were measured using a 5-point Likert-type scale, with each point on the scale represented by a word anchor, with 1 indicating parents doing less of the activity and 5 indicating parents doing more of the activity.

Parental Modeling of Eating Behaviors Scale (PARM; Palfreyman et al., 2014). The PARM was used to examine parent responsive feeding practices such verbal, behavioral, and unintentional role modeling of healthy eating behaviors. PARM is a self-report measure consisting of 15 items using a 7-point Likert-type scale with three anchors ranging from "Strongly disagree," "Neutral," to "Strongly Agree" and higher 
numbers indicating parental affirmation of the modeling behaviors. This measure includes three subscales: verbal modeling that examines how parents model their eating behaviors through verbal communication (6 items; $\alpha=0.86$ ); behavioral consequences explore mothers' intentionally modeling of healthy eating behaviors that their child then copies ( 6 items; $\alpha=0.82$ ); and unintentional modeling that measures parental awareness of behaviors their children have copied, or have in common with their parent, which parents have not intentionally modeled (3 items; $\alpha=0.71$ ).

Families Eat and Activity Overtime Survey (F-Eat Survey; Bauer et al., 2012; Berge, et al., 2012; Bruening et al., 2012). To measure parents' home meal preparation practices, three questions from the F-Eat Survey were completed by parents: The first question asked- who usually prepares food for your family? Parents had to choose all that apply with options such as "Me, Spouse/partner, Child/children, Other adult in the home, Other (please describe)."

The second question asked- how many hours per week do you normally spend preparing food for your family? Parents were asked to provide number of hours per week. The third question asked -how many hours per week does your spouse, partner, or another adult in your household spend preparing food for your family? Parents were asked to provide number of hours per week.

Child fruit and vegetable consumption (USDA Choose MyPlate). Children's fruit and vegetable consumption on a typical day was assessed using the USDA Choose MyPlate recommendations. Parents were asked "how many cups of fruit" and "how many cups of vegetables" does your child eat on a typical day.

\section{Statistical analyses}

Data were analyzed using SPSS version 26 (IBM Corp, 2020). Means, standard deviations, and frequencies were first used to summarize responses. Independent variables that did not have sufficient variability were not included in further analyses. These variables included marital status (78.5\% married), race/ethnicity (88.7\% White), participant gender ( $90 \%$ women), education ( $94.8 \%$ some college or more), work status (89.3\% work fulltime), and food assistance $(1.2-9 \%$ of sample are recipients). To evaluate preliminary associations, Pearson correlations 
were conducted between demographics, other parental beliefs and practices (e.g. parent weight, child weight concern), and other variables of interest (e.g. meal preparation, child fruit and vegetable consumption) with both responsive and controlling feeding practices. Significant associations $(\mathrm{p}<0.05)$ with coefficients greater than 0.10 were noted and included in the regression models. To account for correlations between responsive and controlling feeding practices subscales, in the regression analyses we also included any or all of the four other subscales (there are total of five: verbal modeling, unintentional modeling, behavioral modeling, pressure to eat, restriction) that surpassed the significance threshold during correlation analyses. Non-significant associations were not included in the regression analyses. The dependent variables (feeding practices) included verbal modeling, unintentional modeling, behavioral modeling, pressure to eat, and food restriction. The independent variables (excluding the feeding practices that were controlled for) were selected based on existing literature (Birch et al., 2001, Palfreyman et al., 2014) and from preliminary significant correlations. To account for linearity and multicollinearity, we examined the scatter plots of residuals and reported the variance inflation factor (VIF) for each of the independent predictors.

\section{Results}

This study examined the correlates of parent feeding practices (i.e. responsive and controlling feeding practices). Descriptive analyses (Tables 1 and 2) indicated that parents ( $N=273, M_{\text {age }}=34.46$ years) use verbal $(M=4.83, S D=1.08)$, behavioral $(M=5.24, S D=1.02)$, and unintentional $(M=3.85, S D=1.15)$ role modeling practices, and use restriction $(M=3.40$, $S D=0.73)$ and monitoring $(M=3.86, S D=0.97)$.

Correlations between the variables are located in Supplemental Table S1. Eight independent variables, such as parent age, household income, child weight concern, parent weight, monitoring, child fruit consumption, child vegetable consumption, and time preparing meals, met the significance threshold and were included in the multivariable regression models (Table 3). The feeding practices subscales (i.e. dependent variables) were also correlated with each other (see Supplemental Table S1). Significance threshold were also included in regression 
analyses. Results showed that the proposed model was better at explaining variance in verbal modeling $\left(R^{2}=0.40\right)$, followed by behavioral modeling $\left(R^{2}=0.37\right)$, restriction $\left(R^{2}=0.21\right)$, unintentional modeling $\left(R^{2}=0.25\right)$, restriction $\left(R^{2}=0.22\right)$, and pressure to eat $\left(R^{2}=0.21\right)$. Variance inflation factor (VIF) analyses revealed that the independent variables are not multicollinear (VIF=1.01-1.65). ${ }^{1}$

Results indicated three positive associations of responsive feeding practices: child weight concern, parental monitoring, and child vegetable consumption. Child weight concern was positively associated with unintentional modeling $(\beta=0.17,95 \% \mathrm{CI}[0.12,0.53])$ and parent monitoring was positively associated with verbal modeling $(\beta=0.21,95 \% \mathrm{CI}$ $[0.12,0.34])$. Child vegetable consumption was associated with behavioral modeling ( $\beta=0.22,95 \% \mathrm{CI}[0.17,0.44])$.

Results indicated more statistically significant associations with controlling than responsive feeding practices. For controlling feeding practices, there were two positive and five negative associations. Child weight concern ( $\beta=0.22,95 \%$ CI $[0.13,0.39])$ and parent monitoring ( $\beta=0.13$, $95 \% \mathrm{CI}[0.01,0.19])$ were positively associated with restriction, while child vegetable consumption was negatively associated with parent restriction $(\beta=-0.16,95 \% \mathrm{CI}[-0.27,-0.05])$. Household income $(\beta=-0.13$, $95 \% \mathrm{CI}[-0.30,-0.02])$, child weight concern $(\beta=-0.18,95 \% \mathrm{CI}[-0.45$, $-0.09])$, parent weight ( $\beta=-0.14,95 \% \mathrm{CI}[-0.60,-0.05])$, and child fruit consumption $(\beta=-0.12,95 \% \mathrm{CI}[-0.37,-0.01])$ were negatively associated with pressure to eat.

\section{Discussion}

The purpose of this study was to identify the parent-and child-level correlates of responsive and controlling parental feeding practices for preschoolers in a metropolitan city located in the US. For parent controlling feeding practices (i.e. pressure to eat \& restriction), significant correlates were child vegetable and fruit consumption (child-level characteristics), household income, parent weight, parent monitoring, and child weight concern (parent-level characteristics). For responsive feeding practices

1. VIFs exceeding 5 require further investigation and those exceeding 10 have serious multicollinearity problems and require correction. 
Table 1. Distribution of potential correlates of parent feeding practices.

\begin{tabular}{|c|c|c|c|c|}
\hline Variables & $N$ & $\%$ & Mean & $S D$ \\
\hline \multicolumn{5}{|l|}{ Parent's gender } \\
\hline Male & 27 & 10 & & \\
\hline Female & 244 & 90 & & \\
\hline Parent's age (in years) & 270 & & 34.46 & 5.3 \\
\hline \multicolumn{5}{|l|}{ Child gender } \\
\hline Male & 136 & 50.7 & & \\
\hline Female & 132 & 49.3 & & \\
\hline Child age (in years) & 266 & & 3.95 & .75 \\
\hline \multicolumn{5}{|l|}{ Marital status } \\
\hline Single & 40 & 14.8 & & \\
\hline Married & 212 & 78.5 & & \\
\hline Divorced & 14 & 5.2 & & \\
\hline Other & 4 & 1.5 & & \\
\hline \multicolumn{5}{|l|}{ Race/Ethnicity } \\
\hline White & 235 & 88.7 & & \\
\hline Black or African-American & 17 & 6.2 & & \\
\hline Hispanic or Latino & 3 & 1.1 & & \\
\hline Other & 10 & 3.7 & & \\
\hline \multicolumn{5}{|l|}{ Highest grade } \\
\hline Did not finish high school & 5 & 1.9 & & \\
\hline Finished high school or got GED & 9 & 3.3 & & \\
\hline Some college or training after high school & 46 & 17 & & \\
\hline Finished college & 136 & 50.4 & & \\
\hline Advanced degree (MS, PhD, MD) & 74 & 27.4 & & \\
\hline \multicolumn{5}{|l|}{ Work status } \\
\hline Work fulltime & 241 & 89.3 & & \\
\hline Work part time & 21 & 7.8 & & \\
\hline Stay at home caregiver & 2 & .7 & & \\
\hline Currently unemployed & 3 & 1.1 & & \\
\hline Not working for pay & 3 & 1.1 & & \\
\hline \multicolumn{5}{|l|}{ Food assistance } \\
\hline Food support/stamps & 19 & 7.2 & & \\
\hline EBT & 24 & 9 & & \\
\hline WIC & 15 & 5.7 & & \\
\hline TANF & 6 & 2.3 & & \\
\hline SSI & 3 & 1.2 & & \\
\hline \multicolumn{5}{|l|}{ Annual gross household income } \\
\hline Less than $\$ 45,000$ & 62 & 23.1 & & \\
\hline$\$ 45,000-\$ 90,000$ & 76 & 28.4 & & \\
\hline$\$ 90,000$ or more & 130 & 48.5 & & \\
\hline \multicolumn{5}{|l|}{ Persons living in household } \\
\hline 4 or fewer people & 206 & 76 & & \\
\hline 5 or more people & 65 & 24 & & \\
\hline
\end{tabular}


Table 1. (continued)

\begin{tabular}{|c|c|c|c|c|}
\hline Variables & $N$ & $\%$ & Mean & $S D$ \\
\hline \multicolumn{5}{|l|}{ Parent household role } \\
\hline Mother & 239 & 88.5 & & \\
\hline Father & 26 & 9.6 & & \\
\hline Guardian & 5 & 1.9 & & \\
\hline Child fruit intake (per day) & 268 & & 3.41 & .8 \\
\hline $0-0.5$ cups & 23 & 8.6 & & \\
\hline $1-1.5$ cups & 133 & 49.6 & & \\
\hline 2 cups or more & 112 & 41.8 & & \\
\hline Child vegetable intake (per day) & 267 & & 2.96 & .92 \\
\hline $0-0.5$ cups & 75 & 28.1 & & \\
\hline $1-1.5$ cups & 124 & 46.4 & & \\
\hline 2 cups or more & 68 & 25.5 & & \\
\hline \multicolumn{5}{|l|}{ Who prepares food } \\
\hline Respondent & 246 & 90 & & \\
\hline Spouse & 129 & 47 & & \\
\hline Child/children & 14 & 5 & & \\
\hline Other adult in the home & 4 & 1 & & \\
\hline Other & 3 & 1 & & \\
\hline \multicolumn{5}{|l|}{ Hours per week preparing food } \\
\hline Respondent & 266 & & 6.61 & 3.78 \\
\hline Spouse, partner, or other adult & 259 & & 3.15 & 3.34 \\
\hline \multicolumn{5}{|c|}{ Child Feeding Questionnaire (CFQ) variables } \\
\hline Parent responsibility & 270 & & 4.33 & .65 \\
\hline Parent weight & 270 & & 3.15 & .40 \\
\hline Child weight & 270 & & 2.92 & .34 \\
\hline Child weight concern & 270 & & 1.38 & .62 \\
\hline Parent restriction & 270 & & 3.40 & .73 \\
\hline Parent pressure to eat & 269 & & 2.47 & .96 \\
\hline Parent monitoring & 269 & & 3.86 & .97 \\
\hline \multicolumn{5}{|c|}{ Role Modeling Scale (PARM) variables } \\
\hline Verbal modeling & 269 & & 4.83 & 1.08 \\
\hline Unintentional modeling & 269 & & 3.85 & 1.15 \\
\hline Behavioral modeling & 269 & & 5.24 & 1.02 \\
\hline
\end{tabular}

CFQ items were measured using a 5-point Likert-type scale, with 1 indicating parents doing less of these practices and 5 indicating parents doing more of these practices. CFQ subscales i.e. pressure to eat and restriction represents parent controlling feeding practices. PARM scales were measured using 7-point Likert-type scale with higher numbers indicating parental affirmation of the modeling behaviors. PARM subscales i.e. verbal, unintentional, and behavioral represents responsive feeding practices. 
Table 2. Regression of parent feeding practices on correlates.

\begin{tabular}{|c|c|c|c|c|c|}
\hline \multirow[b]{2}{*}{ Variable } & \multicolumn{3}{|c|}{ Responsive feeding practices (PARM) } & \multicolumn{2}{|c|}{ Controlling feeding practices (CFQ) } \\
\hline & Verbal & Unintentional & Behavioral & Pressure to eat & Restriction \\
\hline & \multicolumn{5}{|c|}{$\beta \pm$ standard error } \\
\hline Parent age & $-0.04 \pm 0.01$ & - & - & $-0.11 \pm 0.01$ & - \\
\hline Household income & - & - & - & $-0.13 \pm 0.07^{*}$ & - \\
\hline Child gender & - & - & - & - & - \\
\hline Child age & - & - & - & - & - \\
\hline Child weight concern & - & $0.17 \pm 0.11^{\star *}$ & - & $-0.18 \pm 0.09 * *$ & $0.22 \pm 0.07^{\star * *}$ \\
\hline Parent weight & $-0.10 \pm .14$ & - & $-0.04 \pm 0.13$ & $-0.14 \pm 0.14$ * & - \\
\hline Responsibility & - & - & - & - & - \\
\hline Monitoring & $0.21 \pm .06^{\star \star \star}$ & $-0.08 \pm 0.07$ & & & $0.13 \pm 0.04^{\star}$ \\
\hline Child fruit consumption & - & - & - & $-0.12 \pm 0.09 *$ & - \\
\hline Child vegetable consumption & - & - & $0.22 \pm 0.07^{\star \star \star}$ & $-0.09 \pm 0.08$ & $-0.16 \pm 0.06^{\star *}$ \\
\hline Time prepping meals & $0.05 \pm .04$ & $0.02 \pm 0.05$ & - & - & - \\
\hline Verbal modeling (PARM) & - & $0.18 \pm 0.07^{\star \star}$ & $0.43 \pm 0.05^{\star * \star}$ & $0.06 \pm .07$ & $0.12 \pm .04$ \\
\hline Unintentional modeling (PARM) & $0.15 \pm .05^{* *}$ & - & $0.23 \pm 0.05^{\star * \star}$ & $0.06 \pm 0.05$ & $0.13 \pm .04^{\star}$ \\
\hline Behavioral modeling (PARM) & $0.42 \pm .06^{* * *}$ & $0.27 \pm 0.07 * * *$ & - & - & - \\
\hline Pressure to eat (CFQ) & $0.08 \pm .06$ & $0.14 \pm 0.07^{\star}$ & - & - & $0.24 \pm 0.04^{\star * *}$ \\
\hline Restriction (CFQ) & $0.11 \pm .08^{*}$ & $0.13 \pm 0.10^{*}$ & - & $0.29 \pm 0.08^{* * *}$ & - \\
\hline Adjusted $\mathrm{R}^{2}$ & 0.40 & 0.25 & 0.37 & 0.21 & 0.22 \\
\hline Variance Inflation Factor (VIF) range & $1.06-1.30$ & $1.02-1.65$ & $1.01-1.20$ & $1.11-1.29$ & $1.09-1.31$ \\
\hline
\end{tabular}

Variance inflation factors (VIF) under 5 are appropriate and low in multicollinearity. Boxes with dashes (-) indicate nonsignificance of variable during initial correlation analyses and variables were not included in regression analyses. ${ }^{*} \mathrm{p}<0.05 ;{ }^{* *} \mathrm{p}<0.01 ;{ }^{* * *} \mathrm{p}<0.001$

(i.e. unintentional, verbal, \& behavioral role modeling), significant correlates were child vegetable consumption, child weight (child-level characteristics) and monitoring (parent-level characteristics). Findings of the current study adds to the feeding practices literature suggesting that parent feeding practices involves bidirectional interactions whereby feeding practices can influence and/or respond to child eating behaviors and vice versa. A recent study has indicated the importance of considering bidirectional associations between mothers' feeding practices and child eating behaviors (Jansen et al., 2018). Focus should be on correlates to improve or reduce controlling feeding practices.

Although limited, consistent with existing studies (Palfreyman et al., 2014), results of the current study showed that increased child vegetable consumption was associated with increased parent behavioral role 
modelling. This is an encouraging and important finding given that existing studies have reported vegetables tend to be among the least preferred types of foods among young children (Cooke et al., 2003) and that children show high levels of food neophobia, which has been associated with lower vegetable intake (Fisher and Dwyer, 2016). It is likely that parents in the current study are consuming vegetables in front of their children (Vereecken et al., 2010). This repeated observational exposure of eating vegetables in front of children by primary caregivers have shown to develop vegetable preferences, acceptance (Fisher and Dwyer, 2016), and consumption (Fisher et al., 2002) among children. Moreover, it is also possible that children are responding and adapting well to eating vegetables which serves as the reinforcement for parents to continue to offer these foods, suggesting that future studies should include child-level factors when examining correlates of feeding practices. Parents avoid repeatedly offering new vegetables to children who show externalizing temperaments (e.g. hyperactive and aggressive) to avoid negative interactions (Vollrath et al., 2012). The current study adds to the feeding practices literature suggesting that parent behavioral role modelling is important for children vegetable consumption in the home setting and that child eating behaviors (e.g. child vegetable intake) is a critical component when examining the correlates of parent feeding practices and targeting interventions to improve children's vegetable consumption.

Increased child weight was found to be associated with increased parents' unintentional role modelling (i.e. children adopting eating behaviors that parents had not actively modelled). While there are no existing studies that support this finding, it is shown that parents unintentionally act as role models for their children's less healthy food (Palfreyman et al., 2014).

Furthermore, results showed that increased parent monitoring was associated with both increased restriction of foods and increased verbal role modeling in consistent with existing studies (Birch et al., 2001; De Lauzon-Guillain et al., 2009). It is likely that parents in this study are monitoring (i.e. keeping track) children's dietary intake by increasing restriction on children's junk foods and practicing verbal role modeling to encourage children to eat healthy foods such as vegetables. Studies have mentioned that mothers have reported greater monitoring of their children's food intake and ate with children more frequently than 
fathers (Blissett and Haycraft, 2008). Parents use of monitoring practices need further research because existing studies have indicated that monitoring is a form of controlling feeding practice (Birch et al., 2001) while others have suggested moderate use of monitoring practices is beneficial to children's outcomes (Faith et al., 2004).

Regarding controlling feeding practices, consistent with existing research (May et al., 2007), increased parental concern about child's weight was associated with decreased pressure to eat and increased restriction. Increased parent restriction was related to decreased child vegetable consumption. Additionally, more pressure to eat was associated with decreased child fruit consumption which in consistent with the existing studies (Fisher and Birch, 2002; Fisher et al., 2002). It is likely that parents who consume fewer fruits use more pressure in feeding their children (Fisher et al., 2002). Also as reported in the existing literature, parents use pressure to eat when children are underweight/ lighter weight (Keller et al., 2006) or children eat little (Jansen et al., 2017), whereas use of restriction occurs when parents are concerned about children being heavier/overweight (Keller et al., 2006; May et al., 2007), or children have low vegetable intake (Fisher and Birch, 1999a, $1999 b$ ) with an intention to improve children's overall nutritional intake (Cachelin and Thompson, 2013; Francis et al., 2001). It may be advantageous in future research to include child's actual weight status (e.g. underweight, normal weight, overweight or obese) and Body Mass Index (BMI) when examining parent feeding practices to gain a clearer picture of parents' concern about child weight.

It is interesting to note that the results of the current study indicated that increased parent weight is associated with decreased pressure to eat, in contrast with the findings of the existing literature (Haycraft and Blissett, 2008). Existing literature has shown that restriction and pressure to eat are predicted by parent's own eating behaviors, their weight status, children's current weight status, and parent concern about their child's future risk of overweight (Birch and Davison, 2001; Haycraft and Blissett, 2008). Given that the current study did not examine parents' actual weight status (e.g. underweight, normal weight, overweight or obese) and their own eating behaviors, future studies should include these variables to better understand parents' attitude about their weight and children's eating behaviors when examining correlates of parent feeding practices. 
Furthermore, increased household income was associated with decreased pressure to eat, consistent with the literature (Francis et al., 2001; Power et al., 2015). It is likely that parents with resources are not worried about food waste and therefore may not pressure children to finish food on their plate. On the contrary low-income mothers are more likely to pressure their children to eat as a result of experiencing food insecurity (Power et al., 2015).Therefore, it is likely at times when mothers can provide their child with a good meal, they may pressure their children to eat despite the child has indicated that he or she is all done eating. It is also likely that mothers may want their children to consume enough food to meet their daily energy requirements or they feel confident that know better than their child when the child has eaten enough. Another reason might be low-income mothers may pressure the child to eat is to save time or to make sure that the child does not go to bed hungry. There is limited research both qualitative and quantitative to explore the reasons for such finding. Future studies are needed on how education-level and food insecurity moderate the relationship with household income to predict controlling feeding practices such as pressure to eat.

Child gender was not associated with parent feeding practice in the current study. The fact that we found no association supports previous studies (Blissett et al., 2006, Blissett and Haycraft, 2008) which suggested that mothers and fathers do not differ in their use of pressure and restrictive feeding practices or treat their male and female children differently in feeding settings and that mothers tend to report greater monitoring and eating with children than do fathers (Blissett et al., 2006). However, this does not mean that there are no different relationships between food liking and consumption for male and female children. Studies have indicated that girls like and consume fruit and vegetables more than boys (Cooke and Wardle, 2005). Future studies with larger sample size representative of both mothers and fathers would be required to examine child gender and parent feeding practices.

An important limitation of this study is the self-reported nature of the measures. While self-reporting is the practical way to assess behaviors in a large-scale survey, it may be subject to parents' biases. Another limitation is the cross-sectional design of this study which does not allow us to determine causality. Additionally, while there is limited generalizability of the study results because the sample was from a metropolitan city located in the US, and consisted of highly educated and 
primarily White mothers, the results are applicable to similar contexts. While much further work is required with larger datasets to explore this suggestion fully, further examination of responsive feeding practices and child vegetable intake in economically and ethnically diverse samples is warranted. Additionally, given the emerging role of fathers' feeding practices, (Litchford et al., 2020), future studies should also include fathers along with mothers.

Taken together, the results of the current study have implications for Extension and public health professionals (e.g. childhood obesity prevention researchers and nutrition educators) and health professionals (e.g. pediatrician, nurse, dietician). Overall, while we found more correlates of controlling feeding practices (i.e. pressure to eat \& restriction) as compared to responsive feeding practices (i.e. unintentional, verbal, \& behavioral role modeling), the current study has demonstrated and adds to the feeding practices literature suggesting that child-level correlates of parent feeding practices are important and that parent feeding practices involves bidirectional interactions whereby feeding practices can influence and/or respond to children's eating behaviors and vice versa. Findings of this study underscore the need for considering childlevel correlates when planning nutrition programs to improve parental feeding practices. When educating parents about feeding practices, it would be helpful to elicit parents' prior knowledge, belief system, attitude, and assumptions to address misconceptions and offer key reliable sources of educational materials and information on responsive parenting practices and provide feeding advice to parents on how to respond appropriately to children's eating behavior. Parents' responsive feeding practices can establish healthy eating habits among preschoolers early in life which is critical to childhood obesity prevention and the development of children's lifelong healthy eating behaviors whereas controlling feeding practices may be counterproductive and put young children at risk for developing detrimental eating patterns and possible obesity.

Acknowledgments The authors would like to thank all the participants of this study, professors who helped in writing the grant, and the administrative staff for their help and support with data entry and grant management.

Authors' contributions All authors conceived the overall aims of this study. DS conducted the data collection, wrote the introduction, methods, and discussion sections. LRZ completed all data analyses and wrote the results section with all authors 
overseeing all statistical analyses. DAD read, critically reviewed, provided suggestions, and edited the manuscript. All authors contributed to interpretation of the findings. and approved the final manuscript.

Availability of data and materials Data can be made available upon request and after application to the Principal Investigator.

Conflicting interest The authors declare no potential conflicts of interest with respect to this study, the authorship and publication of this study.

Consent and approval This study was approved by the University Institutional Review Board.

Funding This work was supported by the Agriculture and Food Research Initiative (grant number 2011-67002-30202).

\section{Supplemental Material follows the References.}

\section{References}

Bante H, Elliott M, Harrod A, et al. (2008) The use of inappropriate feeding practices by rural parents and their effect on preschoolers' fruit and vegetable preferences and intake. Journal of Nutrition Education \& Behavior 40(1): 28-33.

Bauer KW, Hearst MO, Escoto K, et al. (2012) Parental employment and work-family stress: Associations with family food environments. Social Science and Medicine 75(30): 496-504.

Berge JM, MacLehose R, Loth KA, et al. (2012) Family meals. Associations with weight and eating behaviors among mothers and fathers. Appetite 58(3): 1128-1135.

Birch LL and Davison KK (2001) Family environmental factors influencing the developing behavioral controls of food intake and childhood overweight. Pediatric Clinics of North America 48(4): 893-907.

Birch LL and Fisher JO (2000) Mothers' child-feeding practices influence daughters' eating and weight. American Journal of Clinical Nutrition 71(5): 1054-1061.

Birch LL, Fisher JO, Grimm-Thomas K, et al. (2001) Confirmatory factor analysis of the child feeding questionnaire: A measure of parental attitudes, beliefs, and practices about child feeding and obesity proneness. Appetite 36(3): 201-210.

Blissett J and Haycraft E (2008) Are parenting style and controlling feeding practices related? Appetite 50: 477-485.

Blissett J, Meyer C and Haycraft E (2006) Maternal and paternal controlling feeding practices with male and female children. Appetite 47(2): 212-219.

Brown KA, Ogden J, Vögele C, et al. (2008) The role of parental control practices in explaining children's diet and BMI. Appetite 50(2-3): 252-259.

Bruening M, MacLehose R, Loth K, et al. (2012) Feeding a family in a recession: Food insecurity among Minnesota parents. American Journal of Public Health 102(3): 520-526. 
Cachelin FM and Thompson D (2013) Predictors of maternal child-feeding practices in an ethnically diverse sample and the relationship to child obesity. Obesity 21(8): 1676-1683.

Centers for Disease Control and Prevention (2014) Progress on Children Eating More Fruit, Not Vegetables. Available at: http://www.cdc.gov/vitalsigns/fruit-vegetables/index.html (accessed 30 June 2020).

Cooke L and Wardle J (2005) Age and gender differences in children's food preference. British Journal of Nutrition 93(5): 741-746. DOI: 10.1079/bjn20051389.

Cooke L, Wardle J and Gibson EL (2003) Relationship between parental report of food neophobia and everyday food consumption in 2-6-year-old children. Appetite 41: 205-206.

De Lauzon-Guillain B, Musher-Eizenman D, Leporc E, et al. (2009) Parental feeding practices in the United States and in France: Relationships with child's characteristics and parent's eating behavior. Journal of the American Dietetic Association 109(6), 1064-1069.

Faith MS, Scanlon K, Birch LL, et al. (2004) Parent-child feeding strategies and their relationships to child eating and weight status. Obesity Research 12(11): 1711-1722.

Fisher J and Birch L (1999a) Restricting access to foods and children's eating. Appetite 32(3): 405-419.

Fisher J and Birch L (1999b) Restricting access to palatable foods affects children's behavioral response, food selection, and intake. American Journal of Clinical Nutrition 69(6): 1264-1272.

Fisher JO and Birch LL (2002) Eating in the absence of hunger and overweight in girls from 5 to 7 year of age. American Journal of Clinical Nutrition 76: 226-231.

Fisher JO and Dwyer JT (2016) Next steps for science and policy on promoting vegetable consumption among us infants and young children. Advances in Nutrition 7(1): 261S-271S.

Fisher JO, Mitchell DC, Smiciklas-Wright H, et al. (2002) Parental influences on young girls' fruit and vegetable, micronutrient, and fat intakes. Journal of the American Dietetic Association 102: 58-64.

Francis LA, Hofer SM and Birch LL (2001) Predictors of maternal child-feeding style: Maternal and child characteristics. Appetite, 37(3): 231-243.

Fryar CD, Carroll MD and Ogden CL (2018) Prevalence of overweight, obesity, and severe obesity among children and adolescents aged 2-19 years: United States, 1963-1965 through 2015-2016.

Golan M (2006) Parents as agents of change in childhood obesity from research to practice. International Journal of Pediatric Obesity 1(2): 66-76.

Goldman RL, Radnitz CL and McGrath RE (2012) The role of family variables in fruit and vegetable consumption in preschool children. Journal of Public Health Research 1(2): 143-148.

Haines J, Downing KL, Tang L, et al. (2018) Associations between maternal concern about child's weight and related behaviors and maternal weight-related parenting practices: A cross-sectional study. International Journal of Behavioral Nutrition and Physical Activity 15(1): 9.

Haycraft EL and Blissett JM (2008) Maternal and paternal controlling feeding practices: Reliability and relationships With BMI. Obesity 16, 1552-1558.

Hughes SO, Power TG, Fisher JO, et al. (2005) Revisiting a neglected construct: Parenting styles in a child-feeding context. Appetite 44(1): 83-92.

IBM Corp. (2020) SPSS Statistics for Windows (Version 26) (IBM Corp., Armonk, N.Y., USA). 
Jansen E, Williams KE, Mallan KM, et al. (2018) Bidirectional associations between mothers' feeding practices and child eating behaviours. International Journal of Behavioral Nutrition and Physical Activity 15(3): 1-11.

Jansen PW, de Barse LM, Jaddoe VWV, et al. (2017) Bi-directional associations between child fussy eating and parents' pressure to eat: Who influences whom? Physiological Behavior 176: 101-106.

Keller KA, Pietrobelli A, Johnson SL, et al. (2006) Maternal restriction of children's eating and encouragements to eat as the 'non-shared environment': A pilot study using the child feeding questionnaire. International Journal of Obesity 30(11): 1670-1675.

Larson N and Story M (2009) A review of environmental influences on food choices. Annals of Behavioral Medicine 38(Suppl 1): S56-S73.

Litchford A, Roskos MRS, Wengreen, et al. (2020) Influence of fathers on the feeding practices and behaviors of children: A systematic review. Appetite 147(1).

May AL, Donohue M, Scanlon KS, et al. (2007) Child-Feeding strategies are associated with maternal concern about children becoming overweight, but not children's weight status. Journal of the Academy of Nutrition and Dietetics 107(7): P1167-1174.

Palfreyman Z, Haycraft E and Meyer C (2014) Development of the parental modelling of eating behaviours scale (PARM). links with food intake among children and their mothers. Maternal and Child Nutrition 10: 617-629.

Patrick H, Nicklas TA, Hughes SO, et al. (2005) The benefits of authoritative feeding style: Caregiver feeding styles and children's food consumption patterns. Appetite 44: 243-249.

Plano Clark VL and Creswell JW (2010) Understanding Research: A Consumer's Guide. Upper Saddle River, NY: Pearson Education, Inc.

Power TG, Hughes SO, Goodell LS, et al. (2015) Feeding practices of low-income mothers: How do they compare to current recommendations? International Journal of Behavioral Nutrition and Physical Activity 12: 34.

USDA ChooseMyPlate. U.S. Department of Agriculture. How many fruits and vegetables are needed? Available at: https://www.choosemyplate.gov/eathealthy/vegetables

Vaughn AE, Ward DS, Fisher JO, et al. (2016) Fundamental constructs in food parenting practices: A content Map to guide future research. Nutrition Review 74(2): 98-117.

Vereecken C, Rovner A and Maes L (2010) Associations of parenting styles, parental feeding practices and child characteristics with young children's fruit and vegetable consumptions. Appetite 55(3): 589-596.

Vollrath ME, Stene-Larsen K, Tonstad S, et al. (2012) Associations between temperament at age 1.5 years and obesogenic diet at ages 3 and 7 years. Journal of Developmental Behavioral Pediatrics 33(9): 721-727.

Wyse R, Campbell E, Nathan N, et al. (2011) Associations between characteristics of the home food environment and fruit and vegetable intake in preschool children: A cross-sectional study. BMC Public Health 11: 938.

\section{Supplemental Material follows.}


STROBE Statement—Checklist of items that should be included in reports of cross-sectional studies

\begin{tabular}{|c|c|c|c|}
\hline & $\begin{array}{l}\text { Item } \\
\text { No }\end{array}$ & Recommendation & $\begin{array}{c}\text { Page } \\
\text { No }\end{array}$ \\
\hline \multirow[t]{2}{*}{ Title and abstract } & 1 & $\begin{array}{l}\text { (a) Indicate the study's design with a commonly used term in the title or } \\
\text { the abstract }\end{array}$ & 1 \\
\hline & & $\begin{array}{l}\text { (b) Provide in the abstract an informative and balanced summary of what } \\
\text { was done and what was found }\end{array}$ & 1 \\
\hline
\end{tabular}

\section{Introduction}

\begin{tabular}{|c|c|c|c|}
\hline Background/rationale & 2 & $\begin{array}{l}\text { Explain the scientific background and rationale for the investigation being } \\
\text { reported }\end{array}$ & $2,3,4$ \\
\hline Objectives & 3 & State specific objectives, including any prespecified hypotheses & 3 \\
\hline \multicolumn{4}{|l|}{ Methods } \\
\hline Study design & 4 & Present key elements of study design early in the paper & 4 \\
\hline Setting & 5 & $\begin{array}{l}\text { Describe the setting, locations, and relevant dates, including periods of } \\
\text { recruitment, exposure, follow-up, and data collection }\end{array}$ & 4,5 \\
\hline Participants & 6 & $\begin{array}{l}\text { (a) Give the eligibility criteria, and the sources and methods of selection } \\
\text { of participants }\end{array}$ & 4 \\
\hline Variables & 7 & $\begin{array}{l}\text { Clearly define all outcomes, exposures, predictors, potential confounders, } \\
\text { and effect modifiers. Give diagnostic criteria, if applicable }\end{array}$ & NA \\
\hline $\begin{array}{l}\text { Data sources/ } \\
\text { measurement }\end{array}$ & $8^{*}$ & $\begin{array}{l}\text { For each variable of interest, give sources of data and details of methods } \\
\text { of assessment (measurement). Describe comparability of assessment } \\
\text { methods if there is more than one group }\end{array}$ & $5,6,7$ \\
\hline Bias & 9 & Describe any efforts to address potential sources of bias & 13 \\
\hline Study size & 10 & Explain how the study size was arrived at & 4,5 \\
\hline Quantitative variables & 11 & $\begin{array}{l}\text { Explain how quantitative variables were handled in the analyses. If } \\
\text { applicable, describe which groupings were chosen and why }\end{array}$ & 7,8 \\
\hline \multirow[t]{5}{*}{ Statistical methods } & 12 & $\begin{array}{l}\text { (a) Describe all statistical methods, including those used to control for } \\
\text { confounding }\end{array}$ & 7,8 \\
\hline & & (b) Describe any methods used to examine subgroups and interactions & NA \\
\hline & & (c) Explain how missing data were addressed & NA \\
\hline & & $\begin{array}{l}\text { (d) If applicable, describe analytical methods taking account of sampling } \\
\text { strategy }\end{array}$ & NA \\
\hline & & (e) Describe any sensitivity analyses & NA \\
\hline
\end{tabular}

\section{Results}

Participants

$13^{*}$

(a) Report numbers of individuals at each stage of study — eg numbers potentially eligible, examined for eligibility, confirmed eligible, included in the study, completing follow-up, and analysed

(b) Give reasons for non-participation at each stage

(c) Consider use of a flow diagram

Descriptive data

14* (a) Give characteristics of study participants (eg demographic, clinical, social) and information on exposures and potential confounders

(b) Indicate number of participants with missing data for each variable of interest

\begin{tabular}{lc}
\hline Outcome data & $15^{*}$ \\
\hline Main results & 16
\end{tabular}

Report numbers of outcome events or summary measures

(a) Give unadjusted estimates and, if applicable, confounder-adjusted estimates and their precision (eg, 95\% confidence interval). Make clear which confounders were adjusted for and why they were included 
(b) Report category boundaries when continuous variables were categorized

\begin{tabular}{llll} 
& \multicolumn{1}{c}{ categorized } & \\
\cline { 2 - 3 } & $\begin{array}{l}\text { (c) If relevant, consider translating estimates of relative risk into absolute } \\
\text { risk for a meaningful time period }\end{array}$ & NA \\
\hline Other analyses & 17 & $\begin{array}{l}\text { Report other analyses done-eg analyses of subgroups and interactions, } \\
\text { and sensitivity analyses }\end{array}$ & NA \\
\hline
\end{tabular}

\section{Discussion}

\begin{tabular}{|c|c|c|c|}
\hline Key results & 18 & Summarise key results with reference to study objectives & 8,9 \\
\hline Limitations & 19 & $\begin{array}{l}\text { Discuss limitations of the study, taking into account sources of potential } \\
\text { bias or imprecision. Discuss both direction and magnitude of any potential } \\
\text { bias }\end{array}$ & 13,14 \\
\hline Interpretation & 20 & $\begin{array}{l}\text { Give a cautious overall interpretation of results considering objectives, } \\
\text { limitations, multiplicity of analyses, results from similar studies, and other } \\
\text { relevant evidence }\end{array}$ & $9-14$ \\
\hline Generalisability & 21 & Discuss the generalisability (external validity) of the study results & 13,14 \\
\hline \multicolumn{4}{|c|}{ Other information } \\
\hline Funding & 22 & $\begin{array}{l}\text { Give the source of funding and the role of the funders for the present } \\
\text { study and, if applicable, for the original study on which the present article } \\
\text { is based }\end{array}$ & 15 \\
\hline
\end{tabular}

*Give information separately for exposed and unexposed groups.

Note: An Explanation and Elaboration article discusses each checklist item and gives methodological background and published examples of transparent reporting. The STROBE checklist is best used in conjunction with this article (freely available on the Web sites of PLoS Medicine at http://www.plosmedicine.org/, Annals of Internal Medicine at http://www.annals.org/, and Epidemiology at http://www.epidem.com/). Information on the STROBE Initiative is available at www.strobe-statement.org. 